\title{
Are microtargeted campaign messages more negative and diverse? An analysis of Facebook ads in European election campaigns
}

\author{
Alberto López Ortega \\ University of Zurich
}

\begin{abstract}
Concerns about the use of online political microtargeting (OPM) by campaigners have arisen since Cambridge Analytica scandal hit the international political arena. In addition to providing conceptual clarity on OPM and explore the use of such technique in Europe, this paper seeks to empirically disentangle the differing behavior of campaigners when they message citizens through microtargeted rather than non-targeted campaigning. More precisely, I hypothesize that campaigners use negative campaigning and are more diverse in terms of topics when they use OPM. To investigate whether these expectations hold true, I use text-as-data techniques to analyze an original dataset of 4,091 political Facebook Ads during the last national elections in Austria, Italy, Germany and Sweden. Results show that while microtargeted ads might indeed be more thematically diverse, there does not seem to be a significant difference to non-microtargeted ads in terms of negativity. In conclusion, I discuss the implications of these findings for microtargeted campaigns and how future research could be conducted.
\end{abstract}

Keywords: microtargeting, campaigns, negativity, topic diversity 


\section{Introduction}

In 2016, Alexander Nix, chief executive officer of Cambridge Analytica - a political consultancy firm - gave a presentation entitled "The Power of Big Data and Psychographics in the Electoral Process". In his presentation, he explained how his firm allegedly turned Ted Cruz from being one of the less popular candidates in the Republican primaries to be the best competitor of Donald Trump. According to Nix's words, they collected individuals' personal data from a range of different sources, like land registries or online shopping data that allowed them to develop a psychographic profile of each citizen in the US. Allegedly, this knowledge of individuals allowed Cambridge Analytica to send campaign messages to American voters matching their personalities through social media. In the attempt of illustrating their work, Nix showed to the audience an interactive map of lowa where he could select and deselect all citizens according to their partisanship, age, gender, interests, personality and even their address and social media profiles.

Independently of the exact rigor of Cambridge Analytica's method, what seems clear is that a new 'science' of campaigning has risen with interesting consequences in widely differing areas such as law, technology, marketing and politics. Driven by big data and computational analytics (Nickerson and Rogers 2014; Tufekci 2014), marketers in general, but parties and candidates specifically, have developed improved means to devise their campaign strategies and, arguably, shape voters' behavior. From a purely political strategy perspective, the assumption is that parties and candidates can now apply a new technique termed online political microtargeting (OPM) (Borgesius et al. 2018). This strategy implies that campaigners have developed a fine-grained knowledge of voters' online behavior and interests that allow them to send individually tailored messages. From this standpoint, the ideal scenario is one where campaigners are able of identifying - and sending - the type of message that would make each voter more attracted to the idea of voting for their candidate or party (or even more importantly, not voting for her opponent). However, the way towards this ideal scenario seems trickier than political consultancy firms like Cambridge Analytica tend to suggest and this is because parties face informational limitations when they implement online political microtargeting (OPM) techniques. These limitations refer to the inevitable fact that it is not always easy and legal to find politically relevant information (such as ideology, turnout intentions or policy positions) in people's internet history or offline sources. This typically drives campaigners to conduct two types of actions. First, they can run complex inference models that imperfectly predict individuals' political leanings. Second, they can rely on third-party tools that microtarget the ads for them. One of the most prominent examples of the latter is the Facebook Ads system that allow advertisers - of all types - to segment their messages to 
Facebook users based on a set of characteristics collected by the social media platform. There is an ever-growing evidence showing that parties in both in US and UK have started implementing this technique in their campaigns (e.g. Anstead, 2017; Barnard and Kreiss, 2013). However, there is little empirical evidence on how differently campaigners behave when they use OPM as compared to when they run classic campaigns, particularly in Europe.

Besides providing a definition of OPM and exploring the state-of-the-art in four European democracies, this paper develops two expectations on how campaigners could be using OPM technique. First, I hypothesize that campaigners talk about more topics when they perform OPM than in the opposite case. I base this argument on the fact that OPM gives campaigners the opportunity to address more detailed topics when they send individualized messages as compared to broadcasted messages. Second, this paper argues that negative campaigning should be used to a greater degree when campaigners perform OPM. The reason for this is that some of the risks of negative campaigning can be reduced since campaigners can hide their attacks from their opponents or opponents' supporters at least to a greater degree.

With the objective of testing these expectations, this paper relies on an original dataset based on a compilation of Facebook ads obtained during first order campaigns in four European countries: the German 2017 Federal Elections, Austrian 2017 Legislative Elections, and Italian and Swedish 2018 General Elections. Since this ad library contains messages that are both microtargeted and non-microtargeted, I am able to test how differently campaigners behave in both cases. The analysis relies on text-as-data techniques such as supervised and nonsupervised methods. The results show that the penetration of microtargeting is only extensive during the last campaign election, in Sweden. From the analytical perspective, the results confirm that microtargeted ads are thematically more diverse that non-microtargeted ads, but there does not seem to be a significant difference in terms of negativity. I discuss the implications of these results in the context of my data and how future research can expand our knowledge.

\section{Online Political Microtargeting: a new technique of campaigning}

\section{Defining Online Political Microtargeting}

Probably because it is a pretty recent phenomenon, there still lacks a clear definition of what (online) political microtargeting means. Some have used the concept without defining it (Hersh and Schaffner 2013; Murray and Scime 2010; Schipper and Woo 2017), while others have provided somehow vague definitions such as a new way to "reach out to voters with the 
most appropriate messages" (Barocas, 2012. p. 31). Similarly, Sides et al., (2013) claim that political microtargeting enables campaigns to identify with great precision receptive audiences and to appeal to them using targeted appeals. According to Gorton (2016, p. 62), political microtargeting involves "creating finely honed messages targeted at narrow categories of voters based on data analysis 'garnered from individuals' demographic characteristics and consumer and lifestyle" (also supported by Borgesius et al., 2018). More thoroughly, some authors claim that microtargeting necessarily relies on predictive models of behavior (Nickerson and Rogers 2014; Rubinstein 2014) based on perceived partisanship and perceived issue positioning (Endres 2016; Endres and Kelly 2018; Hillygus and Shields 2014). Although it has received various names such as "online profiling", "behavioral targeting" or "online behavior advertising", consumer research defines this data-driven online communication as "the practice of monitoring people's online behavior and using the collected information to show people individually targeted advertisements" (Boerman, Kruikemeier, and Zuiderveen Borgesius 2017). Building on this, I argue that OPM is the technique of segmenting online communications based on individual data with the intention of obtaining a political outcome.

The data that is used for OPM could consist of search histories, public records, online purchases, information posted on social media or any other individually-based data available. Likewise, these communications need to be through the internet to be differentiated from offline practices such us microtargeted door-to-door canvassing ${ }^{1}$. But both offline and online microtargeting are different from classical targeting (generally based on geography and media consumption patterns) in the sense that under classical targeting campaigners need to approach a predefined group with heterogenous subjects. This means that classical targeting strategies can hardly allow campaigners to choose which citizens they want to approach. Instead, they can only adapt their message, for example, to the average viewer of a TV program or the attributes of the majority of a crowd in a town. Microtargeting is slightly different in the sense that it gives campaigners the chance to actually customize and shape the audience towards campaigners they want to direct their messages. For instance, while classical targeting gives parties the chance to advertise their pension policies in districts with a dominant majority of elderly voters, OPM would allow campaigners to advertise pension policies to all people of more than 65 in any district which is not a predefined audience group.

\footnotetext{
${ }^{1}$ Not all door-to-door campaigns involve political microtargeting. However, the fact that citizens are addressed individually give campaigners the chance to tailor the messages to individuals' previously assembled characteristics.
} 
Finally, this definition focuses on online microtargeted communications that intend to reach a political outcome ${ }^{2}$.

In practice, OPM consists of two parts that are typically temporally separated: the datacollection process and publication one. Campaigners first aggregate all the individual data they have from voters and then, after designing the campaign strategy, campaigners actually propagate their messages. Alternatively, when they use third-party systems (such as the one of Facebook Ads) to microtarget their campaign ideas they are also relying on a data collection and segmentation that another entity has previously made for them. This is important for two reasons. First, generally the data is not directly required to the microtargeted citizens or at least not explicitly asked for the means of OPM before sending each advertisement. Second, regardless of the legal provisions, the chance of specifying that the communication is based in their private data remains somewhat hidden or infra-primed and otherwise the recipient of the ad do not notice the specificities and the extent of OPM.

\section{What we know about online political microtargeting in Europe?}

Most models distinguish three eras of political campaigning (Norris 2000; Plasser and Plasser 2002; Strömbäck and Kiousis 2014). First, in pre-modern campaigns, candidates met voters in local whistle-stops and announced their political proposals in partisan press, local posters and radio broadcasts tailoring their political messages to the towns' needs. Then, modern campaigns brought mass communication, and so, the battle to dominate the nightly television news transformed into reality. Parties broadcasted their campaigns through generic newspapers advertisements and through rallies covered on national TV, leaving little room for tailored messages. A third era of campaigning is identified when parties start to combine campaigns at a mass level with a sort of geographical targeting that allow them to strategically allocate their campaign efforts (Issenberg 2012). To do so, campaigners started using public opinion surveys and the expertise of consultants. Already in 2004, "candidates and national parties spent unprecedented amounts" on ground-war activities (Hillygus and Monson, 2009, p.1).

A watershed takes place in post-modern campaigning thanks to technological advancements that transformed target-group centered campaigns (targeting) into individual-centered

\footnotetext{
${ }^{2}$ Although the definition is broad and could include any kind of communication with political implications, this project focuses on those microtargeted messages that are run in campaign and, therefore, have as a direct or indirect function gaining electoral support.
} 
campaigns, i.e. microtargeting. ${ }^{3}$ Even if campaigners already purchased banner ads on websites like AOL.com in 2000 and engaged in search engine advertising in 2004, Obama's 2008 campaign was the pioneer in taking advantage of the fact that almost half of the Americans used the internet to gain political knowledge by using social networks such as Facebook, Twitter or YouTube as campaign sites (Cogburn and Espinoza-Vasquez 2011). A change in US campaign regulation allowed parties to access to national records of registered voters and merge it with citizens' data gathered by private companies. This is why in the US 2012 Presidential campaign candidates not only sent electoral messages through the social media but also used OPM for the first time (Barnard and Kreiss, 2013).

However, we know little about the development of OPM in Europe. There is evidence that social media campaigning is becoming increasingly mainstream in the UK (Anstead 2017) and in most countries of Europe (Lilleker et al. 2017). In addition, there are recent studies based on interviews suggesting that European parties are drawing lessons from US experience and make use of similar strategies (Bennett 2018; Kruschinski and Haller 2017; Magin et al. 2017). Nevertheless, the only studies that empirically analyze OPM are case studies in the US (Hersh 2015; Kim et al. 2018) and the UK (Anstead et al. 2018).

Not only the empirics lack but there are also arguments for skepticism about the actual spread of microtargeting in Europe. While the last consumption patterns typically leave a trace on the internet that helps marketers to know what products to offer, the politically relevant information (i.e. ideology, turnout, past voting behavior) that would help political campaigners to segment political messages is generally unavailable on people's internet history. This is why campaign managers are running increasingly sophisticated inference models based on information such as demographics, consumer behavior and individualized public records, if available. Although evidence is rather scarce, the accuracy of these models seem low so far (Endres 2016). This could be partly explained by the fact that there is a mismatch between campaigners' perception of voters and voters' actual interests and traits (Hersh 2015).

Considering that mistargeting (or misinferring) the desired audience might lead campaigners to get penalized by the 'mistargeted' voters (Hersh and Schaffner 2013), there are reasons to suspect that the accuracy of OPM heavily depends on the available data, and so, the potential electoral effects. But what if even reaching the desired electorate with particularly tailored messages based on their personal and political interests and positions does not work in terms of boosting electoral results? Indeed, it could be that citizens react negatively to this type of

\footnotetext{
${ }^{3}$ According to some authors, this watershed gives birth a genuine fourth age of post-post-modern political campaigning (e.g. Kruschinski and Haller, 2017).
} 
online communications because they perceive it as "creepy" (Smit, Van Noort, and Voorveld 2014; Ur et al. 2012). In this sense, citizens could also have differing perceptions of campaigners' use of individualized campaigns and the fact of using them for maximizing votes (Boerman, Kruikemeier, and Zuiderveen Borgesius 2017) and, thereby, have heterogenous reactions to OPM. Additionally, the campaign information that voters receive via OPM could be perceived as incongruent when it turns to be substantially different in any way to what politicians say in the more general mass campaign, even if they do not express inconsistent positions in these two levels of communications. All these arguments might constitute good reasons why candidates in continental Europe might be reluctant to use this campaigning technique. Even more, also European legal and campaign budget constrains (namely as compared to the US privacy laxity and millionaire campaigns) could suggest that Europeans are reluctant to use OPM. To shed some light on this issue, this article will try to answer the overarching question: To what extent are political actors using OPM in Europe?

\section{Expected effects of Online Political Microtargeting on Campaign Messages}

Although we have previously mentioned the fact that OPM entails some risks since campaigners cannot actually deliver their microtargeted ads as accurately as they wished, this does not mean that campaigners behave differently when they perform OPM as compared to classic older campaigns techniques. Particularly, previous research suggests two types of features that might be linked to OPM: topic diversity and negative campaign.

\section{Topic diversity}

In order to understand the strategic potential of OPM and campaigns at the micro-level we first need to understand the implications of campaigning without this technique. In this sense, vote-maximizing theories have classically assumed that campaigners cannot be of everyone's taste. Regardless of whether parties should emphasize an important campaign issue or they should take a strategic issue position, sending univocal messages to an electorate with heterogenous interests comes with a price (Somer-Topcu 2015). This is because prioritizing some issues or holding a certain position irremediably implies pleasing a subset of voters at the expense of alienating likely voters that hold a different set of priorities or a different position ${ }^{4}$.

\footnotetext{
${ }^{4}$ While from an issue emphasis point of view parties have no choice but to assume the costs of highlighting some issues over others, from a positional point of view parties may not only send precise campaign messages but they can also try to give "everything to everyone" by being broad-appealing, depending on their efforts in giving a clear take on a given issue (Somer-Topcu, 2015). Broad-appealing strategy would entail any effort in remaining cryptic about the position that a party or candidate has
} 
Proponents of OPM assume that campaigners have the capacity of accurately knowing voters' priorities and positions and being able to control who is exposed to campaign messages. This is a game changer since it gives campaigners new means to reduce or eliminate the costs of exposing likely voters to opposing ideas or uninteresting issues. I argue, then, that this reduction of costs should lead campaigners not only talk about topics that please the vast majority of the voters, but also to speak about a rather diverse set of topics that might be liked by smaller portions of the electorate. A recent study tried to contribute to this topic by comparing the type of ads that campaigners air both in the mass media and online finding no significant differences (Franz et al. 2020). Although online ads are more likely microtargeted than offline ads, I build on Franz and colleagues' work by arguing that it is microtargeting and not online ads that should be more thematically diverse.

Expectation 1: the topic diversity increases when campaigners microtarget ads as compared to when they do not microtarget them.

\section{Negativity in campaign}

Political actors are not always campaigning positively. There is evidence that negative campaigning is being used in online campaigning (e.g. Momoc, 2011; Johnson \& Perlmutter, 2010). Also, research shows that negative campaign is also present in Western Europe although to a lesser extent than in the US (Hansen and Pedersen 2008; Walter 2014). Nevertheless, research shows negative campaigning is a risk sport since it can backfire to campaigning party if the attacking strategy gets known by the 'victim' or the media. In fact, attackers might end up being presented as weak and desperate because the party sponsored a negative advertisement (Hansen and Pedersen 2008). That is why negative campaigners sometimes choose to hide their identity behind a "stealth group" (Dowling and Wichowsky 2015). Recent research extends that not only attacks can lead to poor results but also negative sentiment (Utych 2018). Utych shows that politicians' use negative tone in their speech lead to harsher evaluations towards them. Following this rationale, it might make sense to use negative affect when the message is microtargeted instead of aired to the wide public since chances that competitors/media might notice and expose it are smaller. There is initial work that would support this idea. Based on a study comparing videos aired both on the internet

about an issue. This blurry position can be conveyed in a variety of ways such as staying quiet, saying one thing and its opposite, switching to another topic or simply being ambiguous. Scholars have shown that although this strategy sometimes translates into broad-based approval because it facilitates voters' projection of their own ideas on the speakers' ones (Callander and Wilson, 2008; Tomz and Van Houweling, 2009) it tends not to be powerful enough to make citizens take the costly decision of reconsidering their vote intention (Krupnikov and Ryan, 2017). 
and TV during the 2004 and 2008 U.S. presidential campaigns, Roberts found more attacks on web-only ads (Roberts 2013). More specifically on ads, Anstead and colleagues (2018) descriptively show more mentions to opponent parties in Facebook ads than in mass party publicity during 2017 general election in the United Kingdom (Anstead et al. 2018). In this article, we extend this intuition by comparing between microtargeted and non-microtargeted ads (instead of online/offline) and focusing on positivity/negativity ratio of messages.

Expectation 2: the positivity/negativity ratio of messages increases in microtargeted Facebook ads as compared to non-microtargeted ones.

\section{Research design}

\section{Description of the dataset}

This paper uses an original dataset based on a compilation of Facebook Ads obtained during first order campaigns in four European countries: the German 2017 Federal Elections, Austrian 2017 Legislative Elections, and Italian and Swedish 2018 General Elections. They have been collected by ProPublica - a US non-profit newsroom - in consortium with media outlets in each of these countries. The result is $\sim 1,000$ ads per country and a total of unique political 4,091 ads.

How is the data collected by ProPublica? Similar to Anstead et al (2018) or Kim et al (2018), media partners asked their readers to download a plug-in that would capture all the Facebook ads they receive ${ }^{5}$. This includes not only the text and images of each of these ads but also the targeting criteria, the identity of the advertiser, the publication date and the number of impressions by the plug-in users. The advantage here is that - unlike in the other two studies mentioned above - the collection of political ads lasted at least 20 days before the elections and that it could be added through a plug-in not only in Chrome but also in Firefox. However, as previous studies using the same method the data presents a challenging feature which is the lack of representivity for all ads, all Facebook users, or all voters. Concretely, the readership of the media partners is very likely biased in terms of political sophistication from the profile of the general public. I argue that this would be a generalizability problem if the study would focus on comparisons between parties, countries, or types of voters/users. Importantly, this study focuses on the comparison between microtargeted and non-

\footnotetext{
${ }^{5}$ The media partners are tagesschau.de, Der Spiegel, Süddeutsche Zeitung and Bayerischen Rundfunk for Germany; Openpolis for Italy; derStandard.at for Austria and National Library for Sweden.
} 
microtargeted ads that are sent via Facebook Ads. I argue that this comparison especially valid given than the two types of ads are subject to the ceteris paribus assumption (both are variables are subject to the same biases). As will be discussed in the conclusion, the generalizability will have to be tested in future studies that can rely on more representative data.

\section{Methodological strategy}

The dataset has been pre-processed by the data collectors. ProPublica used supervised machine learning to remove ads without political content. To that end, users that downloaded their plug-in had to respond a survey in which they were asked about the political nature of Facebook ads. Then, they trained the tagged ads using a Naïve Bayes classifier that automatically rates the untagged ads. The data only includes ads with a probability of being political >=0.7 (Larson et al, 2017). Once non-political ads are discarded, I also remove ads that happen after the elections since we are only interested in political ads that are placed during the election campaign. Also, for interpretability reasons I translated all documents to English by using DeepL $\mathrm{API}^{6}$. Also, for accuracy reasons I decided to remove punctuation, numbers and English stop words from the corpuses.

\section{Operationalization}

In our empirical analysis we focus on one independent and two dependent variables. The independent variable is OPM. I measure OPM (this way) as those ads that feature at least one microtargeting criterion (such as age or region). Apart from this dummy classification the analyses are also done in a continuous manner considering different levels of OPM depending of the number of microtargeting criteria used by the campaigners.

The first dependent variable is topic diversity which is calculated based on Latent Dirichlet Allocation (LDA). After calculating the LDA model of each of the texts, I run four models that represent the four most common metrics for calculating the ideal number of topics that a text contains (Arun et al. 2010; Deveaud, SanJuan, and Bellot 2014; Griffiths and Steyvers 2004; Cao et al. 2009). In general, all these metrics attempt to capture which is the optimal number to divide the information in different groups of topics. Arun et al (2010) measures symmetric KL-Divergence of salient distributions. Cao Juan et al (2009) selects the LDA model based on density. Griffiths and Steyvers (2004) uses the Gibbs sampling algorithm that evaluate the consequences of changing the number of topics in the corpus. Lastly, Deveaud et al (2014)

\footnotetext{
${ }^{6}$ Recent research proves that automatic translation works for comparative texts in different languages (Vries, Schoonvelde, and Schumacher 2018)
} 
estimate the number of latent concepts of a user query by maximizing the information divergence between all pairs of LDA's topics. To measure these metrics I use the package called Idatuning (Nikita and Nikita 2016) while for the calculation of all text parameters I use the text-as-data package quanteda (Benoit et al. 2018).

Negativity is operationalized using a dictionary method of negative sentiment. The sentiment of each word is coded as negative, positive or neutral based on a standard dictionary-based sentiment analysis, Lexicoder Sentiment Dictionary (LSD) (Young and Soroka 2012b) which has been proved to outperform other sentiment dictionaries such as LIWC when coding sentiment in general. Then, the sentiment is aggregated and calculated at the level of each Facebook Ad (Young and Soroka 2012a). Following previous studies I conceptualize expressed sentiment as the logged ratio of positive to negative terms contained in an advertisement (Lowe et al. 2011; Proksch et al. 2019):

$$
\log \frac{p o s+0.5}{n e g+0.5}
$$

By using the logged ratio, I assume that what matters is the relative positivity and negativity instead the absolute numbers.

\section{Results}

In previous section we have seen that very little is known about the extent to which OPM is used in European election campaigns. Hence, the first empirical question is to what degree the campaigns under study have been penetrated by OPM. Figure 1 delivers a straightforward answer. Campaigners seemed to prefer not to use Facebook ads for microtargeting in Austria, Germany and Italy since only a minority of the ads were microtargeted. In those cases, advertisers would then typically select 2-3 criteria. A very different dynamic is observed in the Swedish election campaign, in which the majority of the ads were microtargeted. Indeed, here the distribution is quite homogenous across the levels of microtargeting indicating variation in the way advertisers made use of the possibility to microtargeted the Facebook ads in this country. 


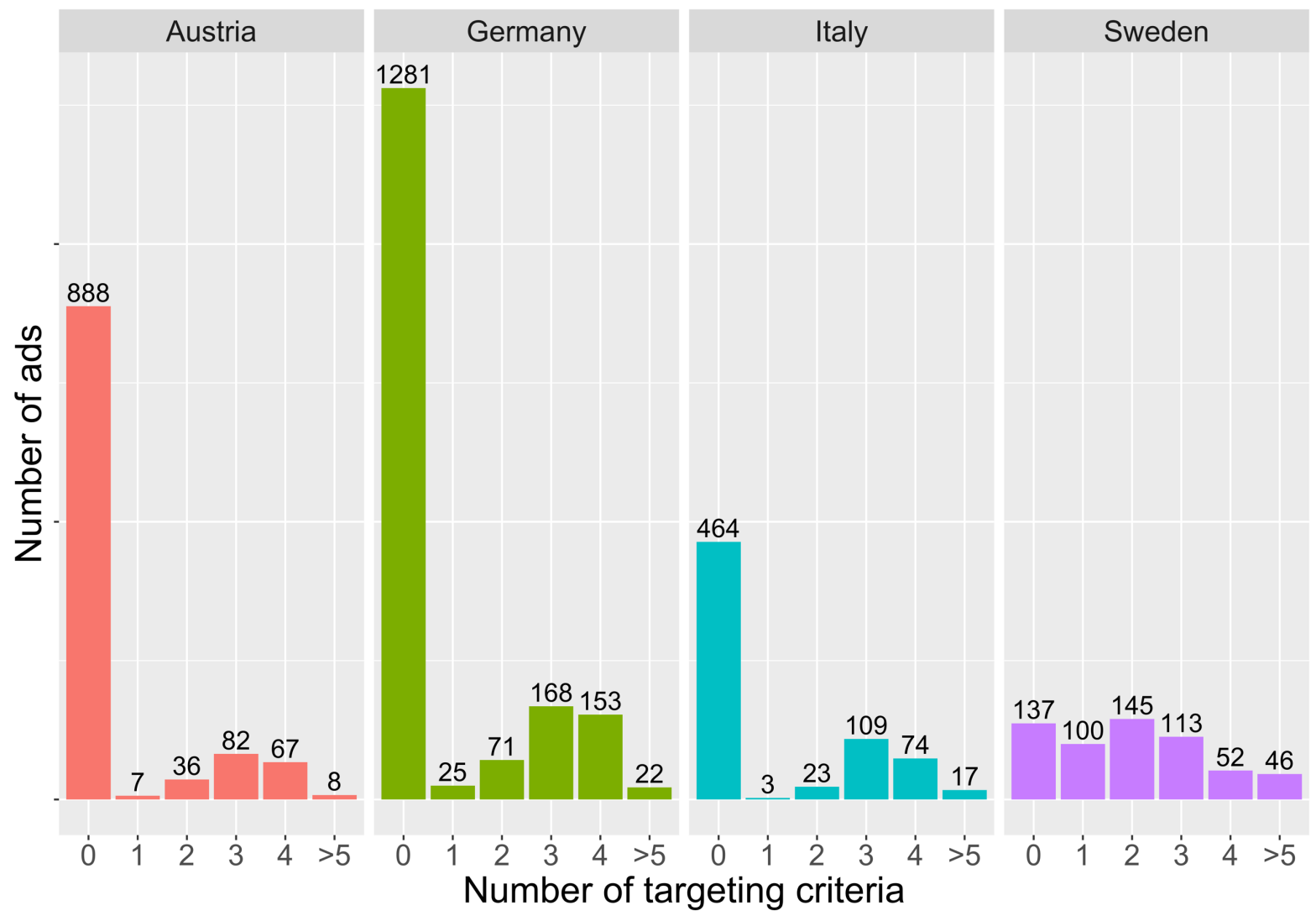

Figure 1. Number of ads sorted by level of microtargeting and country

In the next paragraph, first I will present the results of the number of topics for each of the corpuses (targeted and non-targeted ads) and second, I will introduce the results from the sentiment analysis.

Figure 2 and Figure 3 show the results of the number-of-topics metrics of each of the text corpuses. While the three first metrics (those of CaoJuan2009, Arun2010 and, Deveaud2014) represent the optimal number of topics with low scores, Griffiths2004's metric represents the best fit in terms of number of topics with high estimates. In general, all metrics show that the model benefits from turning from two to more topics, especially in the case of Cao Juan2009. This metric shows that the model drops from 0.5 when one considers that non-targeted ads have more than three topics and targeted ads have more than five topics. Instead, Arun2010 shows very similar estimates for both types of corpuses. The intersection between the estimates of Griffiths2004 and Deveaud2014 portray a very similar thing as with CaoJuan2009. Although both corpuses react similarly to the metrics, the intersection lies on 5.4 topics in the case of the non-targeted ads while the same point lies on 6 in the case of targeted ads. Furthermore, Deveaud2014 suggests 3 as the ideal number of topics in the case of targeted ads, one more topic than the same metric suggests for non-targeted ads. This 
would indicate that microtargeted ads cover a slightly higher number of topics than nonmicrotargeted ads.

A robustness check is conducted focusing on the distribution of topics. Here I run an LDA on the complete sample, count the relative number of posts of each type for each topic, and check whether microtargeted ads are more evenly distributed across topics than non-microtargeted ads. If the former covers more topics, we want to see them being more spread out across topics, in contrast to non-microtargeted ads which should concentrate on fewer topics. I repeated the analysis with varying number of topics finding in every case a quite similar pattern in terms of distribution (Appendix B). These results from the robustness test confirm that while differences in topic diversity between microtargeted and non-microtargeted might exists, these are not striking.

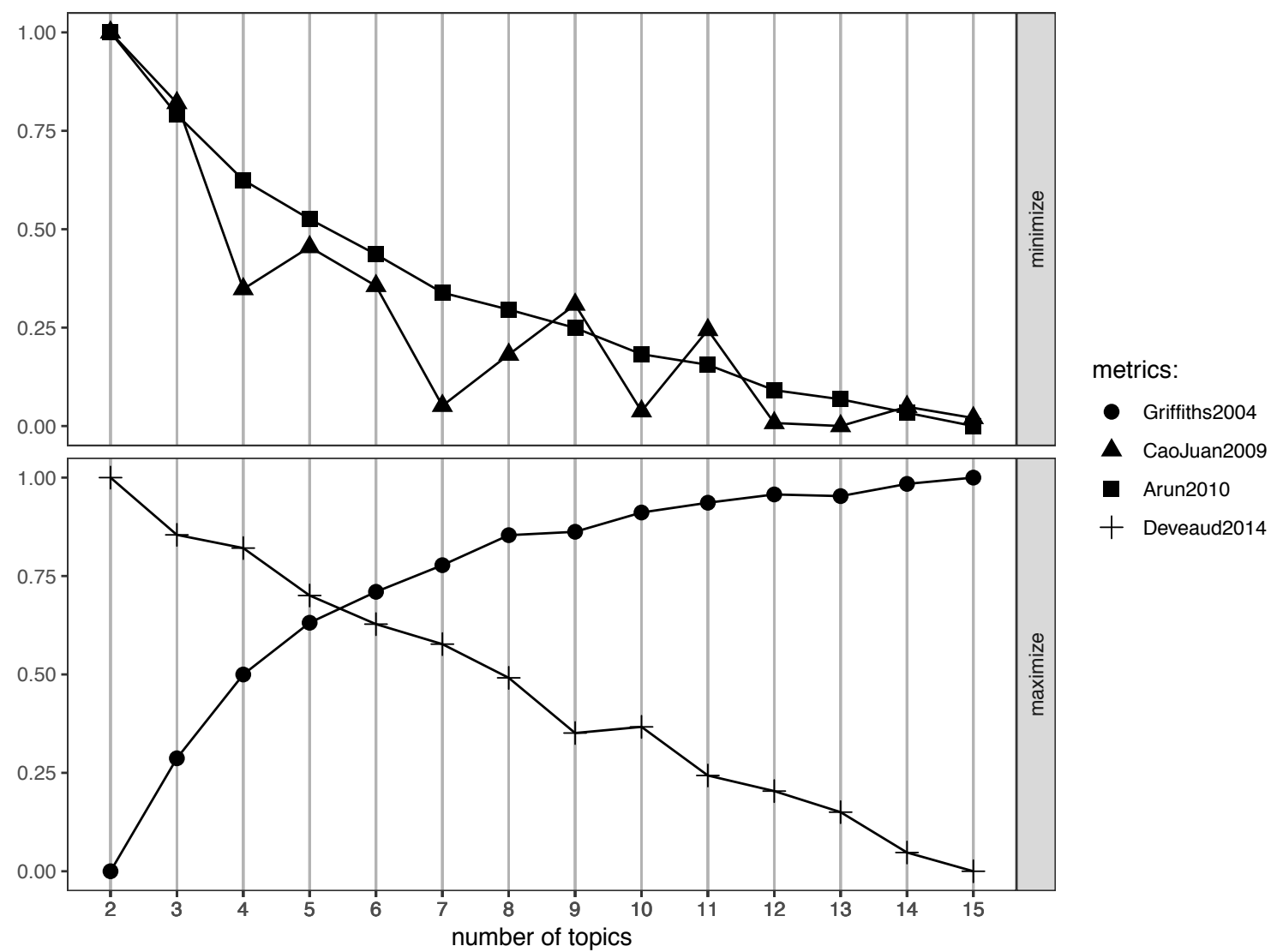

Figure 2. Metrics to calculate the optimal number of topics for non-targeted Ads 


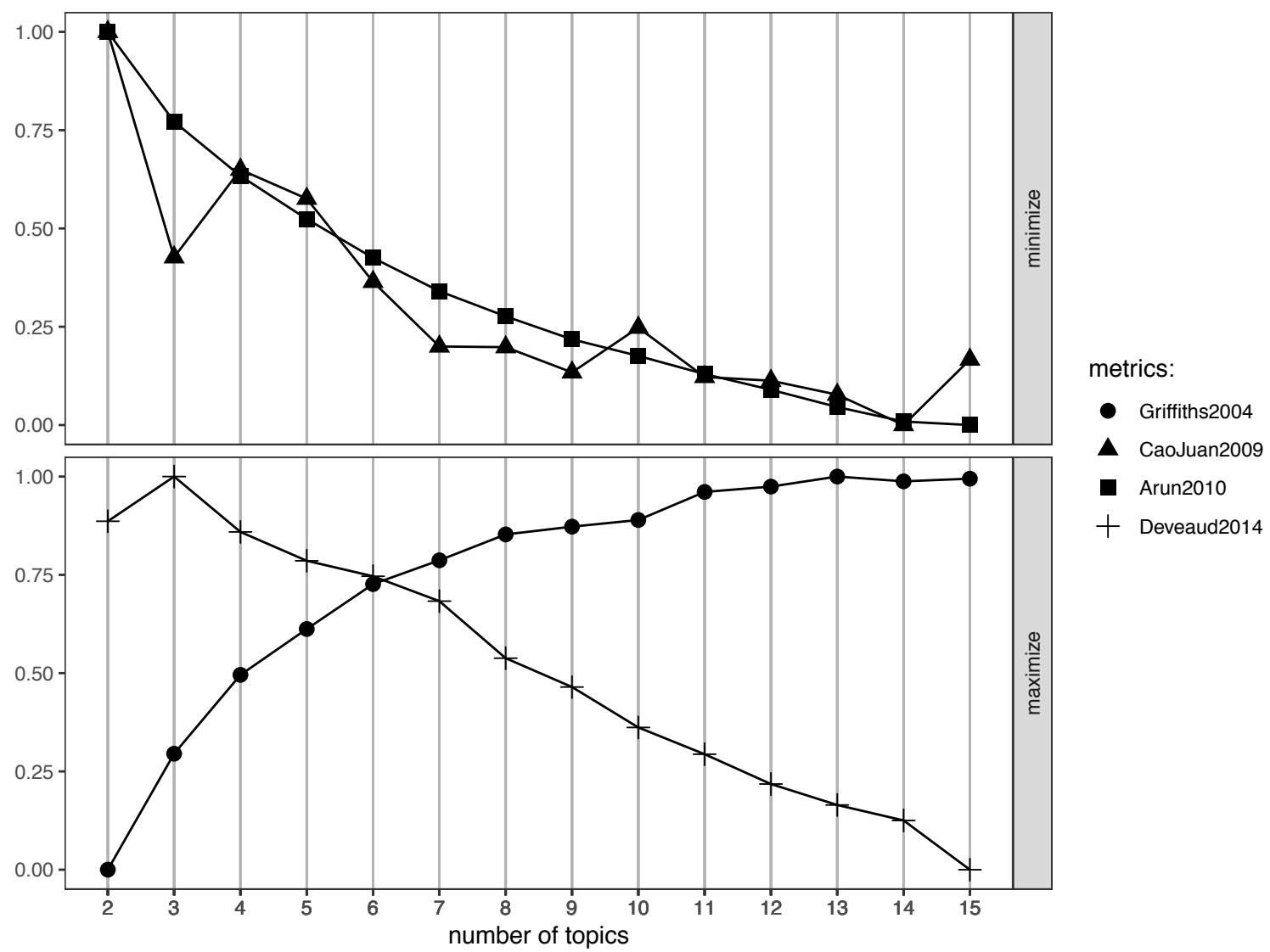

Figure 3. Metrics to calculate the optimal number of topics for targeted Ads

Figure 4 shows the results for the logged ratio of positive to negative terms contained in advertisements ( $y$-axis) divided between targeted and non-targeted ads ( $x$-axis). The overwhelming majority of ads are positive in sentiment. Attacks on opponents are always negative in sentiment. Hence this analysis provides the important finding that OPM does not lead to negative campaigning in the countries under analysis. From a comparative perspective, estimates show that microtargeted ads are more positive than the nomicrotargeted ones, the results are not significant at conventional significance levels. When the same analyses are run by country and actual number of targets criteria, similar results are found (Appendix C). 


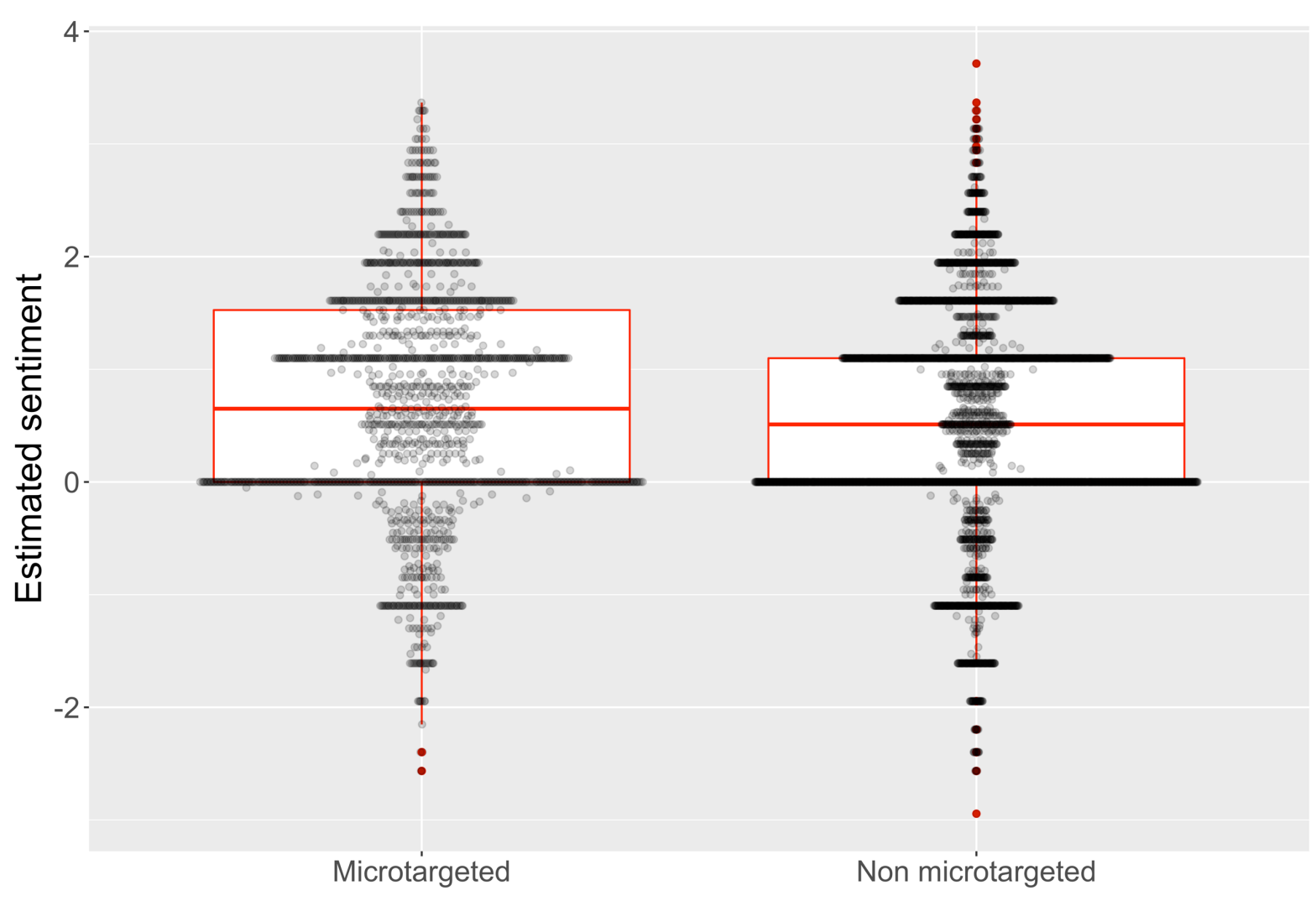

Figure 3. Logged ratio of positive to negative terms contained in advertisements

\section{Conclusions}

This analysis has made three important contributions to the literature. First, it has provided a new definition of OPM. I have defended that OPM is unique in the sense that it allows campaigners to address voters in an individual fashion. Clearly defining OPM is important because the boundaries between OPM and other forms of campaign targeting are less clearcut as one might think. OPM offers the opportunity to customize not only campaign messages but also the audience of these messages. From a political strategy perspective OPM entails a broad range of opportunities for campaigners in the sense of tailoring their communications using different topics, positions and tones.

Second, this is one of the first papers that shows the (ir)relevance of OPM in Europe. I have summarized the small literature and have analyzed an original dataset of Facebook ads of four recent European election campaigns. The results show that campaigners were not eager to microtarget their campaign messages in a systematic fashion. This holds true for the elections that were held during 2017 and in early 2018 (i.e. Germany, Austria, Italy). Contrariwise, Swedish November 2018 elections campaign show a deeper penetration of microtargeting. A potential explanation of this is purely temporal. In line with what other works suggest, European countries would be moving more slowly than the US towards the 
mainstream use of microtargeting during campaigns (Bennett 2018). The fact that Swedish elections coincided with US 2018 Midterm elections could indicate indeed that Swedish campaigns learnt from their counterparts as Benner also suggests. Though, further research on the transmission of campaigning cultures from the US towards Western European countries would be needed to confirm this idea. Also, I note that comparisons by country in this paper need to be taken cautiously given the sample biases that the partner media outlets from each country might involve.

Third, I have analyzed how campaigners use microtargeting. I have expected microtargeted ads being more diverse in terms of topics and more negative. I have found evidence that ads are more diverse in the terms of topics when they are microtargeted. However, the difference in the estimates is not that high as the robustness check showed. In terms of negativity, microtargeted and non-microtargeted ads did not show any significant difference. Nonetheless, more research on more recent campaigns would be needed in order to generalize these results since it could be that these were just the first unexperienced attempts of microtargeting and, thereby, more refined OPM strategies followed during the last elections. The most important limitation of my analysis is that the ads are not a representative sample of all campaign ads. In line with a large experimental literature I have assumed that the bias in the sample does not impact the mutual relationships between variables. However, as is well known, this assumption can be violated. Recently, important progress has been made in getting access to more representative samples of Facebook ads. Hence, future research that is able to draw on more representative data might want to replicate the findings from this article, which is that OPM does lead to more topic diversity but not negative campaigning.

\section{References}

Anstead, Nick. 2017. "Data-Driven Campaigning in the 2015 United Kingdom General Election." The International Journal of Press/Politics 22 (3): 294-313. https://doi.org/10.1177/1940161217706163.

Anstead, Nick, João Carlos Magalhães, Richard Stupart, and Damian Tambini. 2018. "Political Advertising on Facebook: The Case of the 2017 United Kingdom General Election."

Arun, R., V. Suresh, C. E. Veni Madhavan, and M. N. Narasimha Murthy. 2010. "On Finding the Natural Number of Topics with Latent Dirichlet Allocation: Some Observations." In Advances in Knowledge Discovery and Data Mining, edited by Mohammed J. Zaki, Jeffrey Xu Yu, B. Ravindran, and Vikram Pudi, 391-402. Lecture Notes in Computer Science. Springer Berlin Heidelberg.

BARNARD, LISA. 2013. "A Research Agenda for Online Political Advertising: Surveying Campaign Practices, 2000-2012," 21.

Barocas, Solon. 2012. "The Price of Precision: Voter Microtargeting and Its Potential Harms to the Democratic Process." In , 31. ACM Press. https://doi.org/10.1145/2389661.2389671. 
Bennett, Colin J. 2018. "Voter Databases, Micro-Targeting, and Data Protection Law: Can Political Parties Campaign in Europe as They Do in North America?" International Data Privacy Law 6 (4): 15.

Benoit, Kenneth, Kohei Watanabe, Haiyan Wang, Paul Nulty, Adam Obeng, Stefan Müller, and Akitaka Matsuo. 2018. "Quanteda: An R Package for the Quantitative Analysis of Textual Data." J. Open Source Software 3 (30): 774.

Boerman, Sophie C., Sanne Kruikemeier, and Frederik J. Zuiderveen Borgesius. 2017. "Online Behavioral Advertising: A Literature Review and Research Agenda." Journal of Advertising 46 (3): 363-76. https://doi.org/10.1080/00913367.2017.1339368.

Borgesius, Frederik J Zuiderveen, Judith Möller, Sanne Kruikemeier, Ronan Ó Fathaigh, Kristina Irion, Tom Dobber, and Balazs Bodo. 2018. "Online Political Microtargeting: Promises and Threats for Democracy." Utrecht Law Review 14 (1): 15.

Cao, Juan, Tian Xia, Jintao Li, Yongdong Zhang, and Sheng Tang. 2009. "A Density-Based Method for Adaptive LDA Model Selection." Neurocomputing, Advances in Machine Learning and Computational Intelligence, 72 (7): 1775-81. https://doi.org/10.1016/j.neucom.2008.06.011.

Cogburn, Derrick L., and Fatima K. Espinoza-Vasquez. 2011. "From Networked Nominee to Networked Nation: Examining the Impact of Web 2.0 and Social Media on Political Participation and Civic Engagement in the 2008 Obama Campaign." Journal of Political Marketing 10 (1-2): 189-213.

Deveaud, Romain, Eric SanJuan, and Patrice Bellot. 2014. "Accurate and Effective Latent Concept Modeling for Ad Hoc Information Retrieval." Document Numérique 17 (1): 61-84. https://doi.org/10.3166/dn.17.1.61-84.

Dowling, Conor M., and Amber Wichowsky. 2015. "Attacks without Consequence? Candidates, Parties, Groups, and the Changing Face of Negative Advertising." American Journal of Political Science 59 (1): 19-36. https://www.jstor.org/stable/24363594.

Endres, Kyle. 2016. "The Accuracy of Microtargeted Policy Positions." PS: Political Science \& Politics 49 (04): 771-74. https://doi.org/10.1017/S1049096516001645.

Endres, Kyle, and Kristin J. Kelly. 2018. "Does Microtargeting Matter? Campaign Contact Strategies and Young Voters." Journal of Elections, Public Opinion and Parties 28 (1): 1-18. https://doi.org/10.1080/17457289.2017.1378222.

Franz, Michael M., Erika Franklin Fowler, Travis Ridout, and Meredith Yiran Wang. 2020. "The Issue Focus of Online and Television Advertising in the 2016 Presidential Campaign." American Politics Research 48 (1): 175-196.

Gorton, William A. 2016. "Manipulating Citizens: How Political Campaigns' Use of Behavioral Social Science Harms Democracy." New Political Science 38 (1): 61-80. https://doi.org/10.1080/07393148.2015.1125119.

Griffiths, Thomas L., and Mark Steyvers. 2004. "Finding Scientific Topics." Proceedings of the National Academy of Sciences 101 (suppl 1): 5228-35. https://doi.org/10.1073/pnas.0307752101.

Hansen, Kasper M., and Rasmus Tue Pedersen. 2008. "Negative Campaigning in a Multiparty System." Scandinavian Political Studies 31 (4): 408-27. https://doi.org/10.1111/j.1467-9477.2008.00213.x.

Hersh, Eitan D. 2015. Hacking the Electorate: How Campaigns Perceive Voters. New York, NY: Cambridge University Press.

Hersh, Eitan D., and Brian F. Schaffner. 2013. "Targeted Campaign Appeals and the Value of Ambiguity." The Journal of Politics 75 (2): 520-34. https://doi.org/10.1017/s0022381613000182.

Hillygus, D. Sunshine, and J. Quin Monson. 2009. "The Ground Campaign: The Strategy and Influence of Direct Communications in the 2004 Presidential Election." Harvard University and Brigham Young University. Working Paper.

Hillygus, D. Sunshine, and Todd G. Shields. 2014. The Persuadable Voter: Wedge Issues in Presidential Campaigns. Princeton University Press. 
Issenberg, Sasha. 2012. The Victory Lab: The Secret Science of Winning Campaigns. Broadway Books.

Kim, Young Mie, Jordan Hsu, David Neiman, Colin Kou, Levi Bankston, Soo Yun Kim, Richard Heinrich, Robyn Baragwanath, and Garvesh Raskutti. 2018. "The Stealth Media? Groups and Targets behind Divisive Issue Campaigns on Facebook." Political Communication, July, 1-27. https://doi.org/10.1080/10584609.2018.1476425.

Kruschinski, Simon, and André Haller. 2017. "Restrictions on Data-Driven Political MicroTargeting in Germany." Internet Policy Review 6 (4). https://policyreview.info/articles/analysis/restrictions-data-driven-political-microtargeting-germany.

Lilleker, Darren G., Karolina Koc-Michalska, Ralph Negrine, Rachel Gibson, Thierry Vedel, and Sylvie Strudel. 2017. "Social Media Campaigning in Europe: Mapping the Terrain." Journal of Information Technology \& Politics 14 (4): 293-98. https://doi.org/10.1080/19331681.2017.1397239.

Lowe, Will, Kenneth Benoit, Slava Mikhaylov, and Michael Laver. 2011. "Scaling Policy Preferences from Coded Political Texts." Legislative Studies Quarterly 36 (1): 12355. https://doi.org/10.1111/j.1939-9162.2010.00006.x.

Magin, Melanie, Nicole Podschuweit, Jörg Haßler, and Uta Russmann. 2017. "Campaigning in the Fourth Age of Political Communication. A Multi-Method Study on the Use of Facebook by German and Austrian Parties in the 2013 National Election Campaigns." Information, Communication \& Society 20 (11): 1698-1719. https://doi.org/10.1080/1369118X.2016.1254269.

Murray, Gregg R., and Anthony Scime. 2010. "Microtargeting and Electorate Segmentation: Data Mining the American National Election Studies." Journal of Political Marketing 9 (3): 143-66. https://doi.org/10.1080/15377857.2010.497732.

Nickerson, David W., and Todd Rogers. 2014. "Political Campaigns and Big Data." Journal of Economic Perspectives 28 (2): 51-74. https://doi.org/10.1257/jep.28.2.51.

Nikita, Murzintcev, and Maintainer Murzintcev Nikita. 2016. Package 'Ldatuning.'

Norris, Pippa. 2000. A Virtuous Circle: Political Communications in Postindustrial Societies. Cambridge: Cambridge University Press. https://doi.org/10.1017/CBO9780511609343.

Plasser, Fritz, and Gunda Plasser. 2002. Global Political Campaigning: A Worldwide Analysis of Campaign Professionals and Their Practices. Greenwood Publishing Group.

Proksch, Sven-Oliver, Will Lowe, Jens Wäckerle, and Stuart Soroka. 2019. "Multilingual Sentiment Analysis: A New Approach to Measuring Conflict in Legislative Speeches." Legislative Studies Quarterly 44 (1): 97-131. https://doi.org/10.1111/lsq.12218.

Roberts, Chris. 2013. "A Functional Analysis Comparison of Web-Only Advertisements and Traditional Television Advertisements from the 2004 and 2008 Presidential Campaigns:" Journalism \& Mass Communication Quarterly, January. https://doi.org/10.1177/1077699012468741.

Rubinstein, Ira S. 2014. "Voter Privacy in the Age of Big Data." Wis. L. Rev., 861.

Schipper, Burkhard C., and Hee Woo. 2017. "Political Awareness, Microtargeting of Voters, and Negative Electoral Campaigning." SSRN Scholarly Paper ID 2039122. Rochester, NY: Social Science Research Network. https://papers.ssrn.com/abstract=2039122.

Sides, John, Daron Shaw, Matt Grossmann, and Keena Lipsitz. 2013. Campaigns \& Elections: Rules, Reality, Strategy, Choice : 2012 Election Update. W.W. Norton.

Smit, Edith G., Guda Van Noort, and Hilde A.M. Voorveld. 2014. "Understanding Online Behavioural Advertising: User Knowledge, Privacy Concerns and Online Coping Behaviour in Europe." Computers in Human Behavior 32 (March): 15-22. https://doi.org/10.1016/j.chb.2013.11.008.

Somer-Topcu, Zeynep. 2015. "Everything to Everyone: The Electoral Consequences of the Broad-Appeal Strategy in Europe: ELECTORAL CONSEQUENCES OF THE 
BROAD-APPEAL STRATEGY." American Journal of Political Science 59 (4): $841-$ 54. https://doi.org/10.1111/ajps.12165.

Strömbäck, Jesper, and Spiro Kiousis. 2014. "6. Strategic Political Communication in Election Campaigns." In Political Communication, edited by Carsten Reinemann. Berlin, Boston: DE GRUYTER. https://doi.org/10.1515/9783110238174.109.

Tufekci, Zeynep. 2014. "Engineering the Public: Big Data, Surveillance and Computational Politics." First Monday 19 (7).

Ur, Blase, Pedro Giovanni Leon, Lorrie Faith Cranor, Richard Shay, and Yang Wang. 2012. "Smart, Useful, Scary, Creepy: Perceptions of Online Behavioral Advertising." In , 1. ACM Press. https://doi.org/10.1145/2335356.2335362.

Utych, Stephen M. 2018. "Negative Affective Language in Politics." American Politics Research 46 (1): 77-102. https://doi.org/10.1177/1532673X17693830.

Vries, Erik de, Martijn Schoonvelde, and Gijs Schumacher. 2018. "No Longer Lost in Translation: Evidence That Google Translate Works for Comparative Bag-of-Words Text Applications." Political Analysis 26 (4): 417-30. https://doi.org/10.1017/pan.2018.26.

Walter, Annemarie S. 2014. "Choosing the Enemy: Attack Behaviour in a Multiparty System." Party Politics 20 (3): 311-323.

Young, Lori, and Stuart Soroka. 2012a. "Affective News: The Automated Coding of Sentiment in Political Texts." Political Communication 29 (2): 205-231. 2012b. "Lexicoder Sentiment Dictionary." McGill University, Montreal, Canada.

\section{APPENDIX A - Description of the dataset}

The dataset is composed of the following variables:

- advertiser: the name of the advertiser (e.g. CDU)

- title: name of the ad (e.g. CDU)

- created_at: date of creation of the ad (e.g. 2017-09-12)

- election_day: election date (e.g. 2017-09-24)

- id: country (e.g. Germany)

- message: textual content of ad (e.g. "vote CDU on Sunday...")

- target_type: the type of targeting criteria used by the advertiser (e.g. age)

- value: the specific targeting value used by the advertiser (e.g. younger than 65) 
APPENDIX B - Descriptive analyses

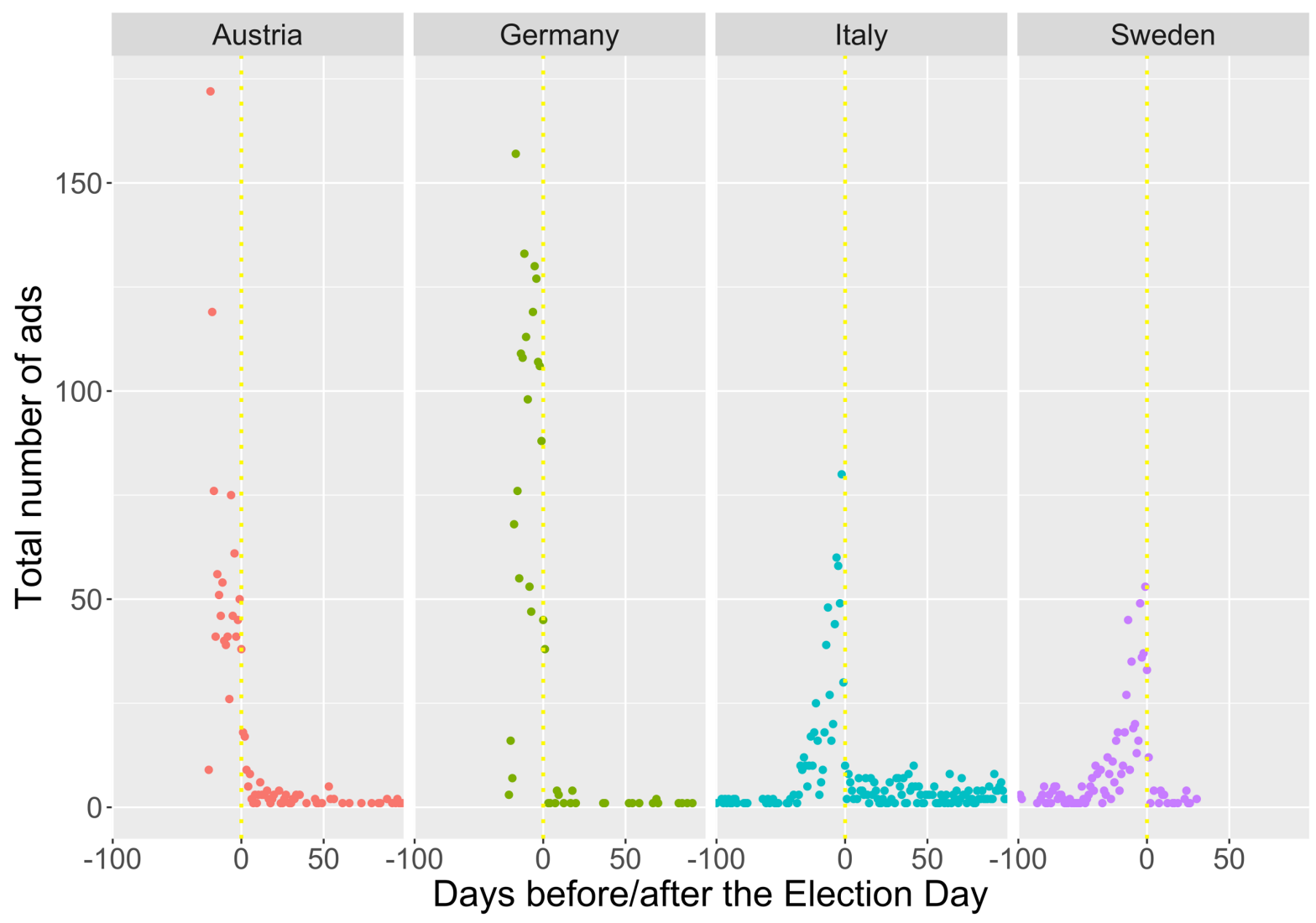

Figure B1. Number of total ads sorted by days before/after the Election Day 


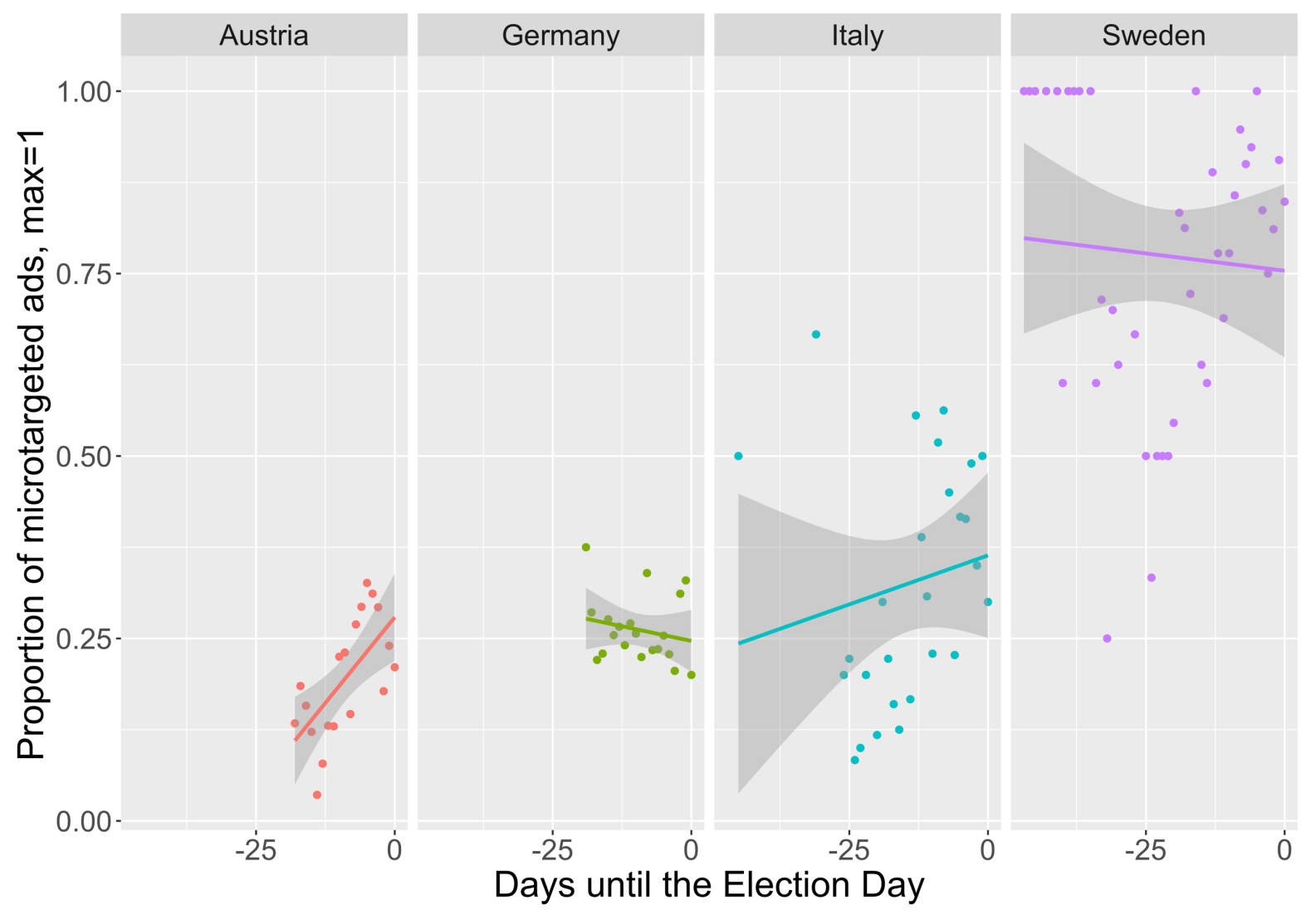

Figure B2. Proportion of microtargeted ads sorted by days before/after the Election Day 


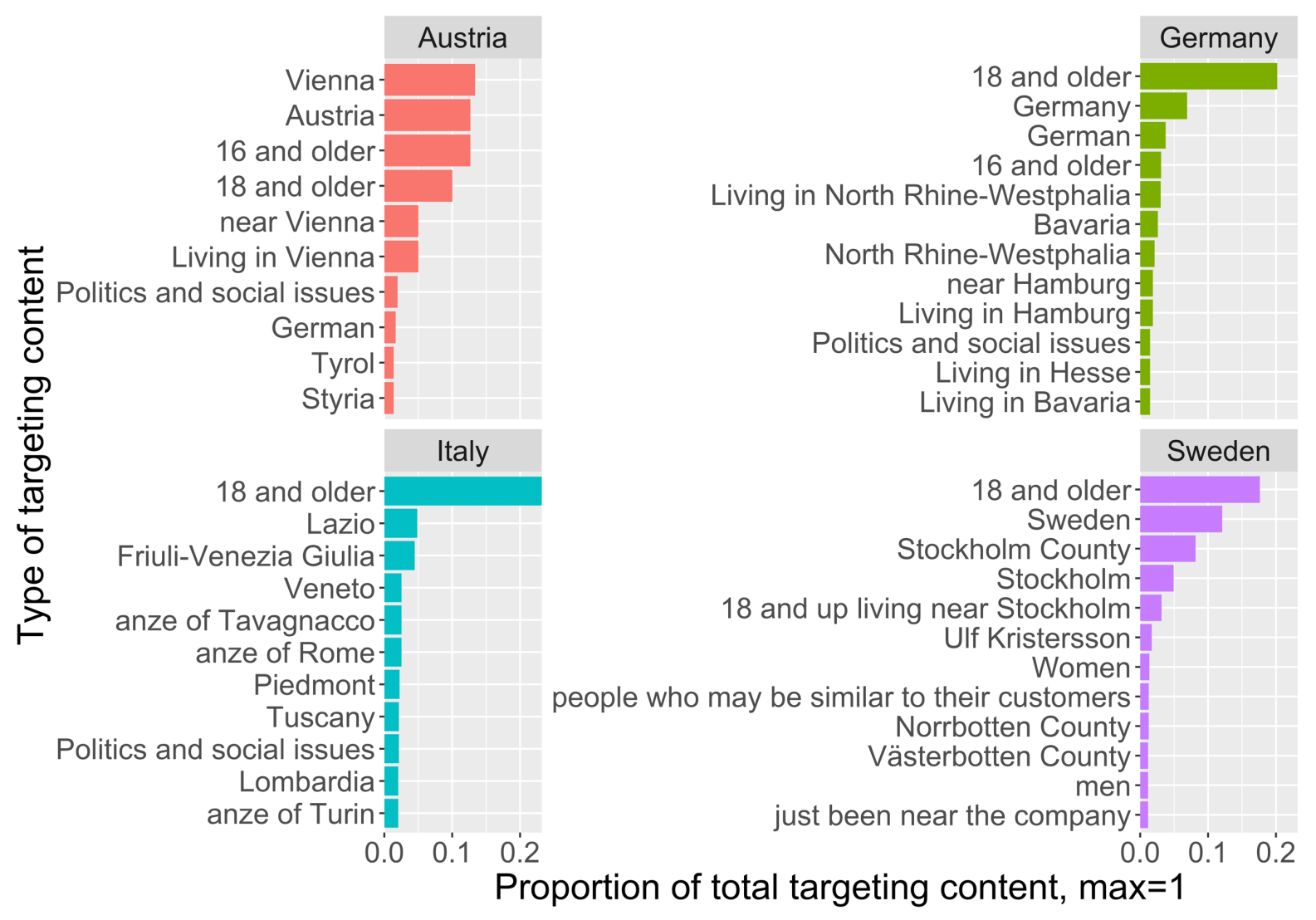

Figure B3. Proportion of microtargeted ads sorted by type of targeting content 


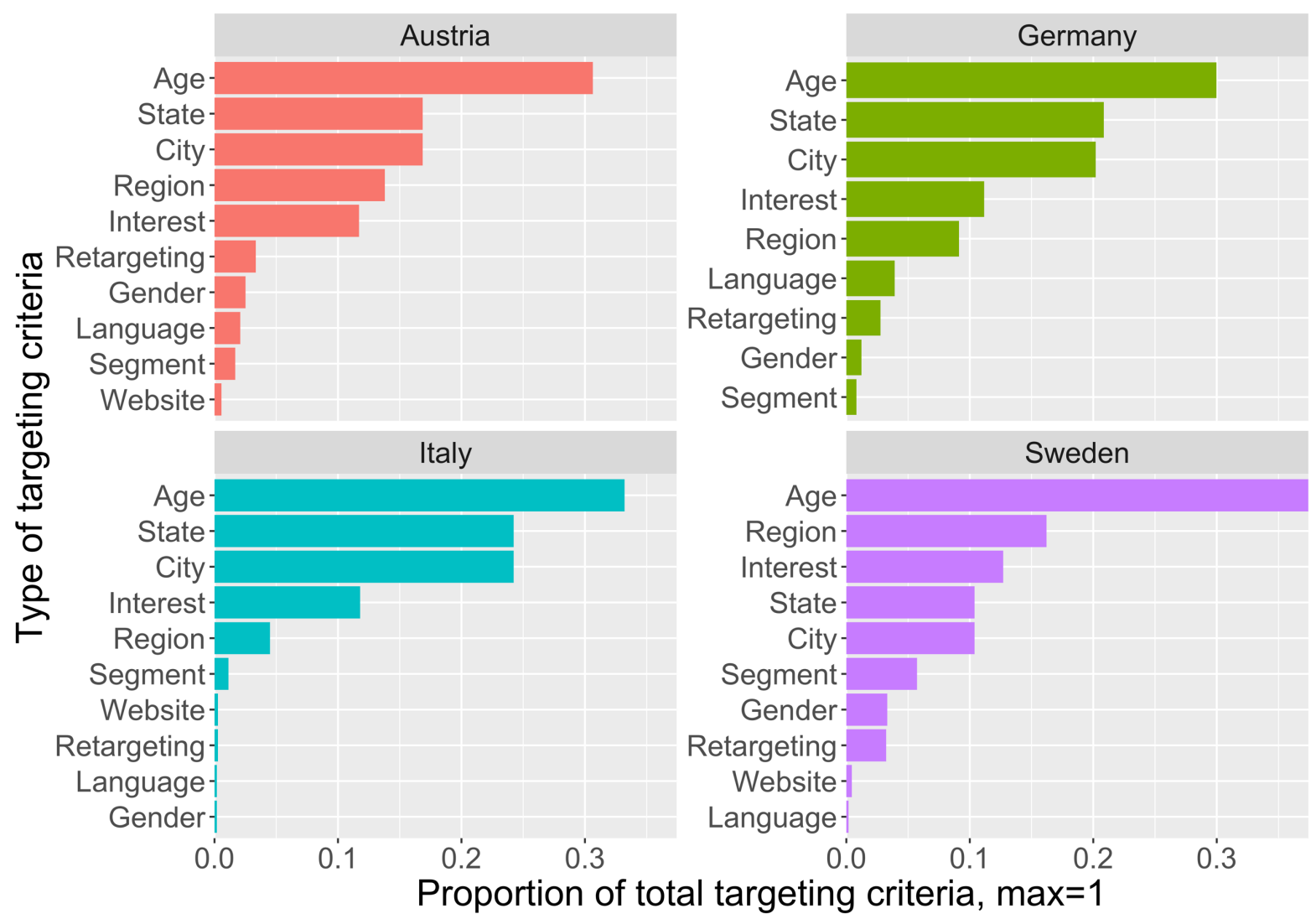

Figure B4. Proportion of microtargeted ads sorted by type of targeting criteria 
continuecdu
진 afd media
show standrome ask \% wants security ovp healieve candidate campaign able $\approx$ money european system voiceplace children democrats £education almost o. long familyulflast support importantyear rights old \& feel council give well better take europe citizens choose politics @joblike many gettry left ${ }^{\text {two }}$ welfare ¿ state school $气$ sd 1 ke many get topday case music : ¿.ّreat

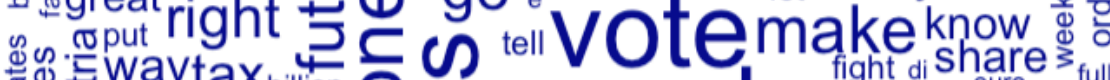

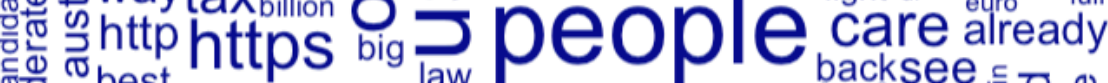
o

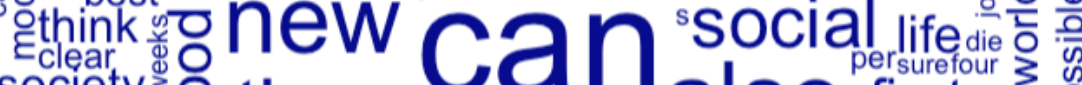
society 3 o time also firstmade: help
food force
always still city sweden 10 W WOrk swedish italy election must green filmtalk real political home come justtoday together highgermanydays ? need even start eu $=0$ said eo since stop september $\$$ government kurz $_{\text {thing }}$ look reduce

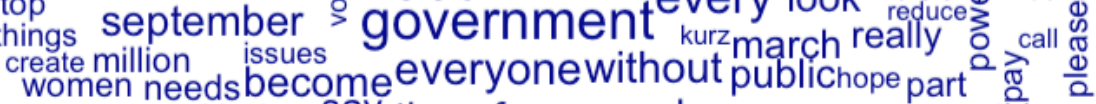
program stockholm say therefore sunday elections something

Figure B5. Wordcloud of main words in the dataset 


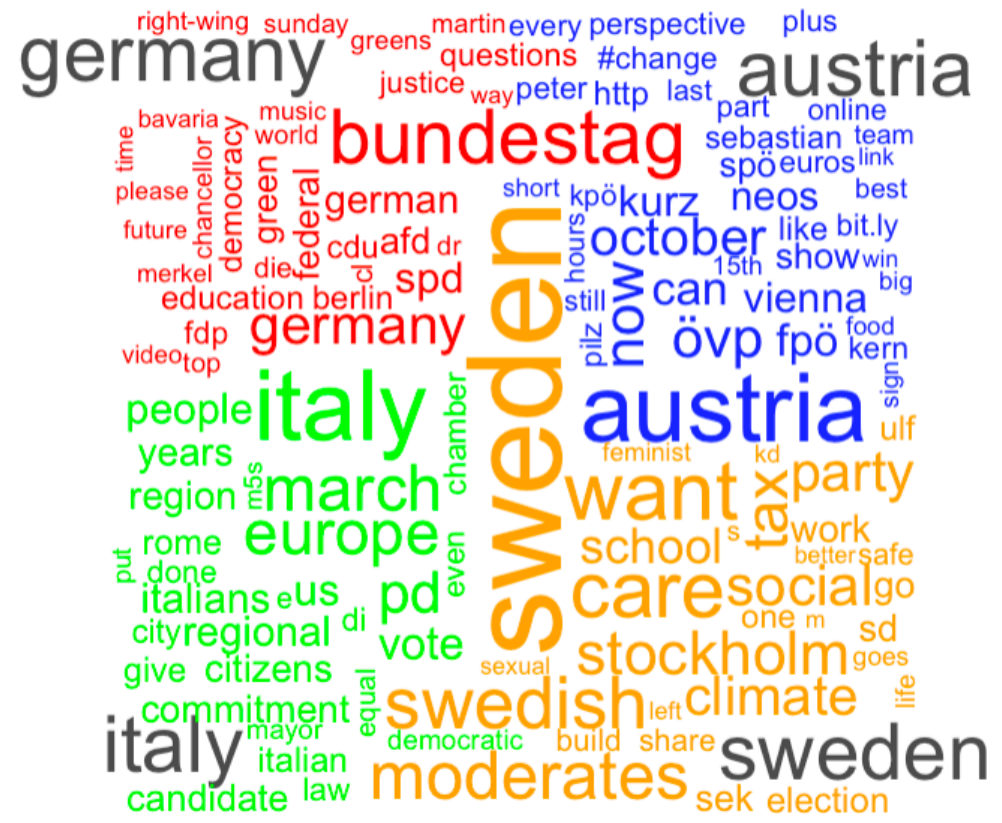

Figure B6. Wordcloud of main words in the dataset by country 
Topic 2: Territory, EU integration

Topic 4: Media

Topic 7: Children and their future

Topic 8: Labor and taxes

Topic 27: environment

Topic 17: vote seeking
Topic 3: Togetherness

"want, policy, must, system, area, country, https, future, also, integration, can, one, eu, asylum, common"

"country, go, together, come, want, back, better, tell, place, talk, friends, like, times, second, force"

"read, video, find, interview, problems, shared, peter, whole, opinion, show, best, article, pilz, year"

"school, children, education, can, important, opportunities, child, high, schools, students, around, municipality, social, plan, good" "tax, euros, work, year, less, pay, million, per, money, billion, income, taxes, pension, lower, costs" "vote, sunday, want, voice, good, choose, can, give, future, voting, make, strong, decide, justice, just" "care, climate, health, council, green, county, environment, need, stockholm, environmental, want, read, able, reduce, transport" 
APPENDIX C- Distribution of microtargeted vs. non-microtargeted ads depending on number of topics

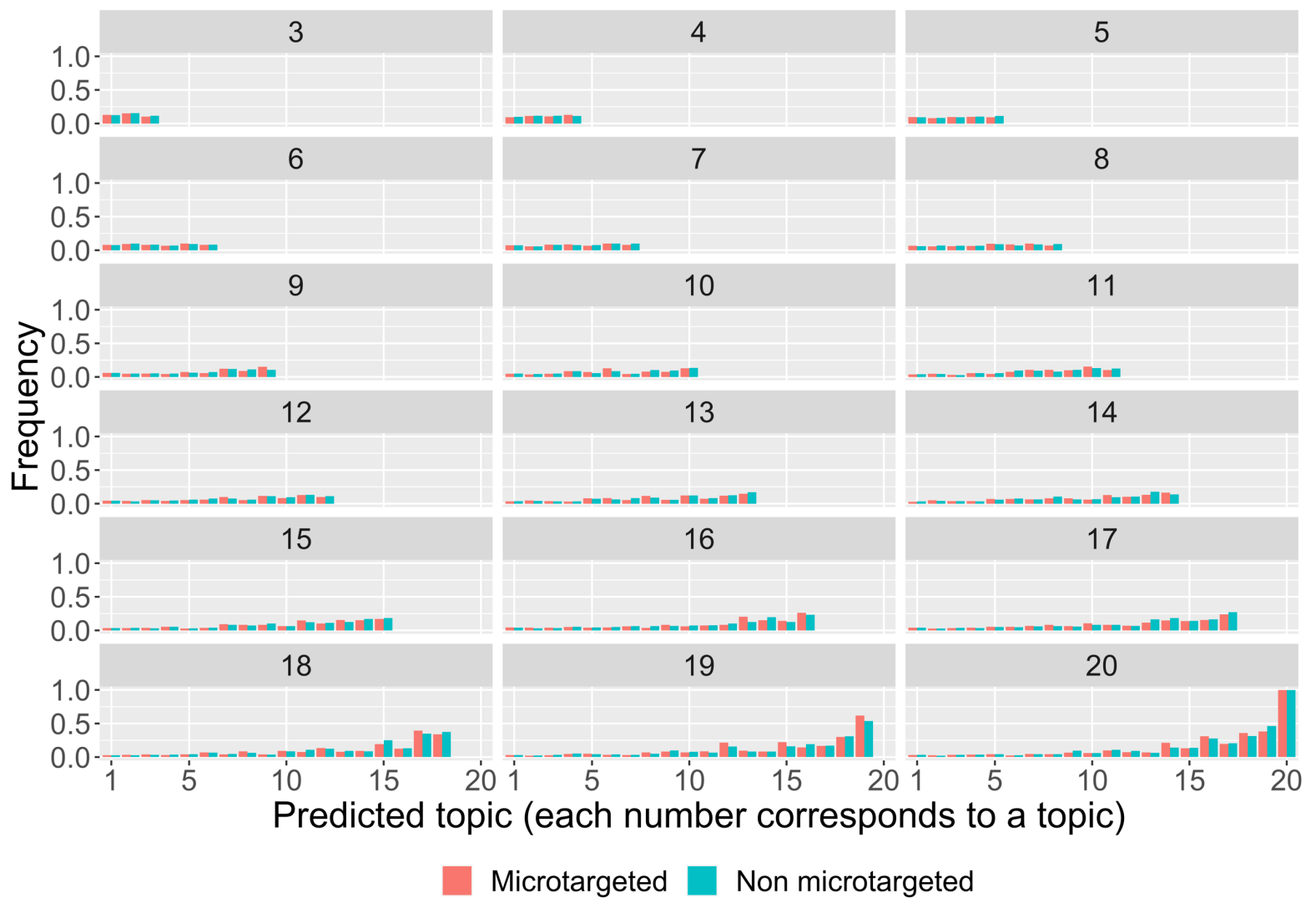

Figure C1. Predicted topic distribution sorted by microtargeted/non-microtargeted ads and different choices of number of topics 
APPENDIX C - Estimated sentiment by level of microtargeting and country

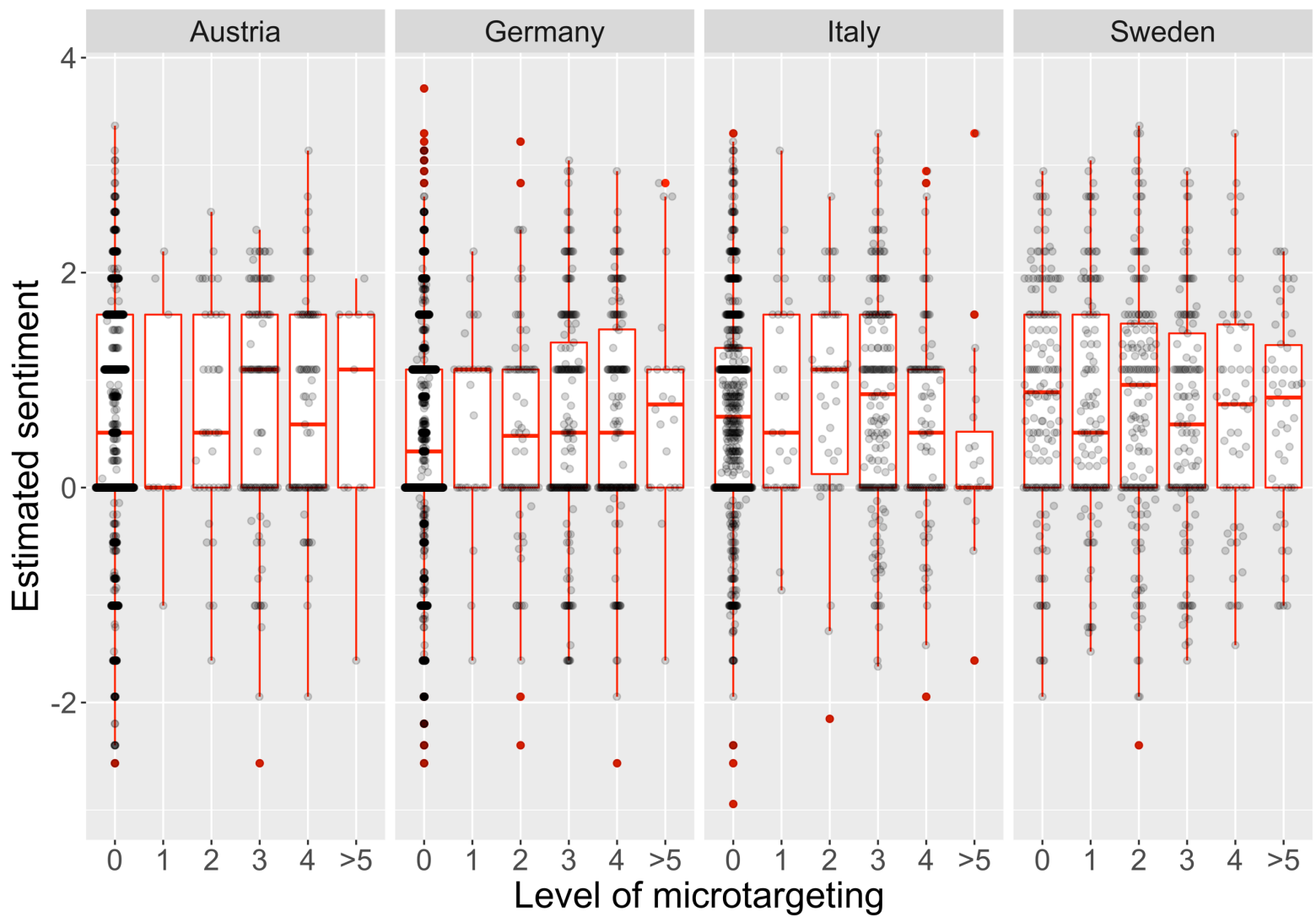

Figure C2. Estimated sentiment sorted by microtargeted/non-microtargeted ads and country 